\title{
CMA phasing out annual General Council meeting
}

- Cite as: CMAJ 2018 July 3;190:E810-1. doi: 10.1503/cmaj.109-5617

Posted on cmajnews.com on June 13, 2018.

$\mathrm{T}$ he Canadian Medical Association (CMA) plans to eliminate its General Council, the sometimes boisterous yearly meeting known as the "Parliament of Medicine" at which delegates debate motions to direct the association's policy development. In its place, the association will hold a new event, called the Health Summit. The final General Council - and the inaugural Health Summit will be held Aug. 20-22 in Winnipeg.

Dr. Brian Brodie, chair of the CMA board of directors, said the move is aimed at making the association more responsive to members and better able to encompass the breadth of what contributes to a healthy population. "We want to move from debate to dialogue, conservative to modern, and exclusive to inclusive," he said.

CMA members have mixed feelings about the change and are waiting to see how it works out in practice. Dr. Trina Larsen Soles, past president of Doctors of BC (but speaking in a personal capacity), said the $B C$ association has always been active in proposing motions. Now that they will not be debated or voted on at General Council, the association is reconsidering how many delegates it needs to send to the Health Summit.

"The provincial associations are asking, 'Where do we fit in?' General Council was our conduit to CMA," she said. "There's a huge experiment in progress, and it is either going to be a resounding success or total failure. I'm hoping for the former."

The Ontario Medical Association said some of its members support the move, but that others were deeply concerned. "While the CMA Board acted with the needs of their organization in mind, these

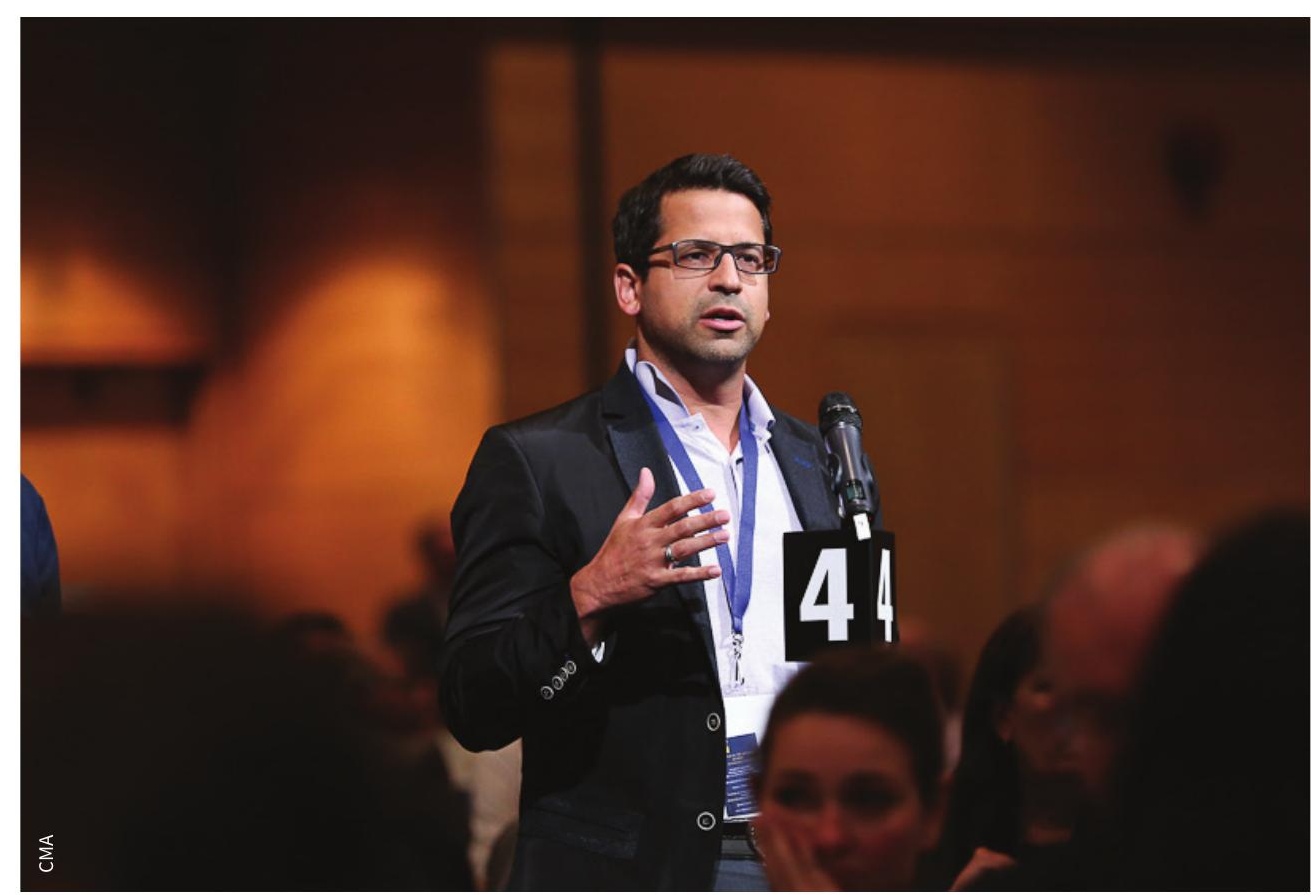

Debates between physicians on the floor of General Council are coming to an end.

moves indicate a significant shift in the relationship between the CMA and the provincial representative medical associations," said OMA chair of the board of directors Dr. Tim Nicholas and president Dr. Nadia Alam in a statement. "This changing relationship has left many wondering about the role the CMA plays as the national voice of physicians. The next few months will show how this relationship evolves. The OMA Board is actively discussing the ramifications of these changes."

This year's General Council will be reduced from several days to two hours and will feature a discussion of the CMA's code of ethics and the association's elections. The CMA is proposing a change to the bylaws that will allow elections to be held electronically and the General Council to be discontinued. The Health Sum- mit, a two-day event preceding General Council, will be structured more like a conventional conference, featuring "inspirational keynote speakers, panel discussions and a marketplace of ideas for participants."

The motions usually presented and debated at General Council will be replaced by a year-round call for member proposals on policy issues, though the mechanism for submitting and debating them has not yet been determined. Members can also form grassroots "Communities of Interest" around various healthrelated issues, which can be a forum for crafting proposals. Brodie said most motions at General Council passed with large majorities and tended to be on inoffensive "motherhood and apple pie" issues. He hopes the new system will 
encourage the association to tackle more controversial topics.

"We've got to move from a three-day event to a continuous conversation," he said. "We need a much more robust dialogue."

Dr. Courtney Howard, an emergency physician in Yellowknife, thinks the Communities of Interest will be a good mechanism for doctors to engage with issues they care about, especially for physicians in remote areas who may not have likeminded colleagues nearby. "Facilitating a distributed structure where doctors can connect will help get things done, and fight feelings of loneliness," she said. "It has the potential to decrease physician burnout and frustration."
Howard is developing a proposal to create a Community of Interest around planetary health. Having communities, rather than individuals, craft motions "can provide some peer review of proposals before they go to the board." But she worries the end of General Council means the interpersonal element of debating motions will be lost. As a delegate for the Northwest Territories, Howard brought forward motions urging CMA to divest from fossil fuel investments multiple times before succeeding. "My motions on environmental health took a lot of building trust with doctors with different opinions," she said. "I'm not sure how the human elements will be incorporated" in the new system.
Dr. David May, a family physician in Powell River, British Columbia, said the CMA, like many organizations, is struggling to engage with grassroots members and the changes could help. But he is concerned that it takes the responsibility for crafting motions away from provincial associations. It could leave the process vulnerable to being hijacked by small special-interest groups to push through policies on controversial topics without much time for debate. "We could lose the carefully measured discussions that go on at provincial associations," he said. "Trolls could take over policy development."

Brian Owens, St. Stephens, NB 